\title{
Pembelajaran Mahārat al-Kalām pada Program Kursus Bahasa Arab Spesial Ramadan di Pondok Pesantren Darul Lughah Waddirasatil Islamiyah, Pamekasan, Madura
}

\author{
Mahbub Humaidi Aziz*, M. Syathibi Nawawi, Muhammad Alfan \\ Universitas Negeri Malang, Indonesia
}
Learning Mahărat al-Kaläm on the Ramadan Special Arabic Course Program at Pondok Pesantren Darul Lughah Waddirasatil Islamiyah, Pamekasan, Madura

\section{E-Mail Address}

mahbubhumaidi.mh@gmail.com

${ }^{*}$ Corresponding Author

\section{Keywords}

Learning mahārat al-kalàm;

Arabic course;

effectiveness;

efficiency

\begin{abstract}
The purpose of this study was to determine the learning process (material, methods, media, and evaluation), effectiveness, and efficiency of learning mahārat al-kalām on the Ramadan Special Arabic course program at Pondok Pesantren Darul Lughah Waddirasatil Islamiyah (PP DLWI), Pamekasan, Madura. Data collection techniques used were observation, interviews, questionnaires, and documentation. Qualitative data were analyzed using descriptive methods, while quantitative data used simple statistics consisting of the stages of preparation, tabulation, and data processing. The results of this study prove that (1) the learning process of mahārat al-kalām consists of materials, methods, media, and evaluations that are tailored to each level; mubtadi, mutawassit, and mutaqaddim; (2) the effectiveness of mahärat al-kalām learning in this program is, the mubtadi' level of $87.33 \%$ (very effective), the mutawassit rate of $95.6 \%$ (very effective), and the mutaqaddim rate of $98 \%$ (very effective); (3) The efficiency of mahärat al-kalām learning in this program is, the mubtadi level of $88.25 \%$ (very efficient), the mutawassit rate of $90.88 \%$ (very efficient), and the mutaqaddim rate of $94.05 \%$ (very efficient).
\end{abstract}

\section{Pendahuluan}

Bahasa Arab merupakan bahasa asing yang sudah banyak digunakan oleh berbagai negara, baik dalam kegiatan formal maupun nonformal. Ghozali (2010), mengutip pendapat Arsyad, menyatakan bahwa bahasa Arab merupakan salah satu bahasa besar di dunia yang dituturkan oleh lebih dari 200 juta umat manusia. Di Indonesia, bahasa Arab merupakan salah satu mata pelajaran wajib yang harus dipelajari di sekolah umum berbasis agama. Bahasa Arab juga banyak dipelajari secara informal, seperti di pondok pesantren, Taman Pendidikan Alquran (TPA), dan lembaga kursus.

Harahap (2017) dalam penelitiannya di STAIN Curup membuktikan bahwa masih banyak mahasiswa yang kebingungan dalam pembelajaran bahasa Arab, seperti mempelajari huruf Arab dan 
kosakata yang sukar untuk dihafalkan. Keterampilan pembelajaran bahasa Arab yang umum dipelajari ada empat, yaitu keterampilan menyimak (mahārat al-istimā̄), keterampilan berbicara (mahārat al-kalām), keterampilan membaca (mahārat al-qirāa'ab), dan keterampilan menulis (mahārat al-kitābah) (Hermawan, 2011, p. 129).

Salah satu aspek penting dalam pengajaran bahasa Arab adalah aspek keterampilan berbicara (mahārat al-kalām). Pengajaran keterampilan berbicara dalam pembelajaran bahasa Arab penting agar peserta didik memeroleh kemampuan berbicara untuk mampu menuangkan ide, gagasan dan perasaan dengan bahasa. Farkhana (2017) menjelaskan bahwa penggunaan mahārat al-kalām dapat mengembangkan daya pikir siswa dengan cara menulis kosakata penting di buku tugas untuk kemudian dihafalkan melalui teknik mubādathah (percakapan) sehingga menjadikan siswa terbiasa untuk berbincang dalam bahasa Arab. Efektivitas dan efisiensi pembelajaran tersebut tentunya tidak dapat lepas dari proses pembelajaran yang terdiri dari strategi belajar, media, maupun evaluasi yang diberikan.

Kursus bahasa Arab di Pondok Pesantren Darul Lughah Waddirasatil Islamiyah (PP DLWI) Pamekasan, Madura, menggunakan sistem pembelajaran yang dibagi ke dalam tiga tingkatan, yaitu mubtadi', mutawassit, dan mutaqaddim. Kegiatan kursus bahasa Arab di PP DLWI ini menjadikan santriwan dan santriwatinya mahir menguasai bahasa Arab secara cepat di bulan Ramadan. Ini tak lepas dari pengaruh sistem dan strategi belajar yang dilaksanakan pada kursus tersebut, seperti munāqashah, mujādalah, dan mubādathah. Atas dasar inilah yang membuat peneliti tertarik untuk menjadikan program kursus bahasa Arab tersebut sebagai bahan penelitian. Bagaimanakah program tersebut dapat menjadikan santriwan dan santriwatinya mahir berbahasa Arab dalam waktu singkat selama 21 hari di bulan Ramadan. Oleh karena itu, penelitian ini bertujuan untuk memaparkan data mengenai proses pembelajaran, efektivitas, dan efisiensi pembelajaran mahārat al-kalām di PP DLWI, Pamekasan, Madura.

\section{Metode Penelitian}

Penelitian ini menggunakan metode deskriptif kualitatif dengan menggambarkan, memaparkan, dan menguraikan objek yang diteliti (Arikunto, 2005, p. 11). Selain itu, melalui studi kasus (case study), responden dalam penelitian ini adalah peserta kursus (santri) dan semua pengajar pada program kursus bahasa Arab spesial Ramadan di PP DLWI, Pamekasan, Madura. Adapun produk yang dihasilkan dalam penelitian ini adalah data (fakta) mengenai proses pembelajaran, efektivitas dan efisiensi pembelajaran mahārat al-kalām terhadap kemampuan berbicara bahasa Arab selama program kursus berlangsung.

Instrumen penelitian ini berupa angket, lembar observasi, pedoman wawancara yang diuji kevalidannya terlebih dahulu oleh ahli, setelah itu dilakukan pengumpulan data. Pengumpulan data dilakukan dengan penyebaran angket kepada pengajar dan peserta kursus. Selain itu, peneliti juga melakukan observasi pada saat pembelajaran kursus mahārat al-kalām berlangsung, melakukan wawancara kepada para pengajar kursus, dan mendokumentasikan pembelajaran yang berlangsung. Data dalam penelitian ini adalah data kualitatif dan kuantitatif. Data kualitatif dianalisis menggunakan metode deskriptif, sedangkan data kuantitatif menggunakan statistik sederhana yang terdiri dari tahap persiapan, tabulasi, dan pengolahan data. 
Pembelajaran Mahārat al-Kalām pada Program Kursus Bahasa Arab Spesial Ramadan

di Pondok Pesantren Darul Lughah Waddirasatil Islamiyah, Pamekasan, Madura

\section{Hasil Penelitian}

A. Proses Pembelajaran Mahārat al-Kalām

1. Buku dan Materi Pembelajaran

Buku yang digunakan pada tingkat mubtadi' adalah Majmü'at al-Lughah al-Arabìyah. Buku ini berisi materi tentang "al-lughah al-'Arabiyah mubimmatun fi al-älam" (pentingnya bahasa Arab di dunia), "á’ilat Rashìd" (keluarga Rasyid), "ḅadiqat al-bayt" (taman rumah), "al-darrājab" (bersepeda), "daftar al-ghiyāb”(absen kelas), "yawm al-aḥad”(hari ahad), "al-biwāyah"(hobi), dan "țälibah nashitah" (peserta yang rajin). Sementara itu, pada tingkat mutawassit, buku yang digunakan adalah al-Muhādathah wa-al-Muțāla'ah jilid 2, al-Majmū'ah al-Lughawiyah, dan alLughah al-Sahafiyah wa-al-'Asriyah. Buku-buku tersebut berisi materi tentang "Ramadān shabr al-șawm"(Ramadan adalah bulan puasa), "al-ijāzah al-sa'iddab"(liburan yang menyenangkan), "mā as'adu bashiran” (orang yang paing bahagia), "al-hadiyyahli-al-nājiḅ”(hadiah untuk orang sukses).

Buku yang digunakan pada tingkat mutaqaddim adalah al-Muḥādathab wa-al-Muțāla' ab jilid 3. Buku tersebut berisi materi tentang "tawfir al-nuqüd fi al-bank" (menabung uang di bank), "saḥb al-nuqūd fì al-bank" (penarikan uang di bank), "al-barlamān" (parlemen), "ma'mal al-lughab" (laboratorium bahasa), "al-dars al-idâfî" (pelajaran sore), "al-irshādāt fì al-bạ̣th al-ilmī" (pengarahan tentang karya ilmiah), "kitābat al-bahth al-ilm̄”"(penulisan karya ilmiah), "al-isti'dād li-munāqashat al-baḥth al-ilmı̄" (persiapan diskusi karya ilmiah), "mabrajān al-'Arab" (festival bahasa arab), "al-hafl al-riyadi" (perayaan olah raga), "mūsim al-ma'rad" (musim pameran), "albank al-Islāmī"(bank syari'ah), "al-intikhāb al-'àm"(PEMILU), dan "al-ḥamlah al-intikhābìyah" (kampanye pemilu).

\section{Metode dan Strategi yang Digunakan dalam Pembelajaran Mahārat al-Kalām}

Metode dan strategi yang digunakan dalam pembelajaran mahārat al-kalām untuk tingkat mubtadi' adalah dengan menggunakan berbagai metode pembelajaran. Metode-metode tersebut antara lain: metode langsung, muhādathah (tanya jawab, menghafal dialog, percakapan terpimpin atau bebas), bifž al-ibārāt (menghafal ungkapan), muḅạdarah (pidato), taqdim al-qișah (bercerita), masrab̧iyah/tamthïlīyah (drama), permainan (tebak kata dan tebak gambar, kata dan kalimat beruntun). Untuk tingkat mutawassit, juga menggunakan berbagai metode pembelajaran, antara lain muqābalah (wawancara), munāqashah (diskusi), muhādathah (percakapan), taqdìm al-qiș̣ah (bercerita), khibrah muthìrah (mengungkapkan pengalaman pribadi), hifz al-ibārāt (menghafal ungkapan), masrahīyab/tamthïlìah (drama), mujädalab (debat), dan permainan (tebak kata dan gambar, bermain peran, dan kalimat beruntun). Sementara itu, di tingkat mutaqaddim juga menggunakan berbagai metode pembelajaran, antara lain: khibrah muthirah (mengungkapkan pengalaman pribadi), muqābalah (wawancara), munāqashah (diskusi), muḥādathah (percakapan), taqdim al-qișah (bercerita), hifž al-ibārāt (menghafal ungkapan), masrahīyab/tamthïlīyah (drama), mujädalah (debat), ta'bìr musawwar (mengungkapkan sesuatu melalui gambar), dan permainan (tebak gambar, tebak dan bermain peran, dan kalimat beruntun). 


\section{Media Pembelajaran Mahārat al-Kalām}

Media pembelajaran yang digunakan pada tingkat mubtadi, mutawassit, dan mutaqaddim adalah papan tulis, gambar, lukisan, foto, VCD/LCD, dan Proyektor. Media papan tulis adalah media utama dalam pembelajaran mụ̧ādathah yang memiliki keistimewaan tersendiri dibanding dengan media pembelajaran yang lain, yaitu sangat mudah penggunaannya. Setiap guru sama sekali tidak mendapatkan kesulitan dalam menggunakan media ini, di samping tidak membutuhkan dana yang besar untuk pengadaannya. Media gambar lukisan dan foto juga sangat menunjang dalam pembelajaran muhādathah. Sementara itu, media VCD/LCD dan proyektor pada pembelajaran sangat baik karena dengan kehadiaran media tersebut perhatian peserta akan lebih besar terhadap pembelajaran mahārat al-kalām.

\section{Bentuk Evaluasi Pembelajaran Mahārat al-Kalām}

Evaluasi pembelajaran mahārat al-kalām dilakukan dengan tes lisan. Di tingkat mubtad̄̄' dilakukan dengan cara menilai percakapan secara langsung dalam topik pelajaran muhādathah. Percakapan tersebut dimulai dengan peserta yang paling pandai, kemudian dilanjutkan oleh peserta yang berada pada level di bawahnya untuk contoh pada peserta lainnya. Evaluasi pada tingkat mutawassit dilakukan dengan cara menilai proses diskusi peserta didik yang diminta untuk maju ke depan kelas. Sementara itu, evaluasi pada tingkat mutaqaddim lebih bersifat monolog, seperti penilaian kegitan bercerita atau berpidato di depan kelas menggunakan bahasa Arab dengan tema bebas.

\section{B. Efektivitas Pembelajaran Mahārat al-Kalām}

Tabel 1. Efektivitas pembelajaran mahārat al-kalām pada tingkat mubtadi'

\begin{tabular}{ccccc}
\hline \multirow{2}{*}{ Nomor Soal } & \multicolumn{2}{c}{ Jumlah Responden } & \multicolumn{2}{c}{ Persentase } \\
\cline { 2 - 5 } & Ya & Tidak & Ya & Tidak \\
\hline 1 & 30 & 0 & $100 \%$ & $0 \%$ \\
2 & 30 & 0 & $100 \%$ & $0 \%$ \\
3 & 27 & 3 & $90 \%$ & $10 \%$ \\
4 & 24 & 6 & $80 \%$ & $20 \%$ \\
5 & 27 & 3 & $90 \%$ & $10 \%$ \\
6 & 25 & 5 & $83,3 \%$ & $16,7 \%$ \\
7 & 25 & 5 & $83,3 \%$ & $16,7 \%$ \\
8 & 24 & 6 & $80 \%$ & $20 \%$ \\
9 & 24 & 6 & $80 \%$ & $20 \%$ \\
10 & 26 & 4 & $86,7 \%$ & $13,3 \%$ \\
\hline
\end{tabular}

Tabel 2. Efektivitas pembelajaran mahārat al-kalām pada tingkat mutawassit

\begin{tabular}{ccccc}
\hline \multirow{2}{*}{ Nomor Soal } & \multicolumn{2}{c}{ Jumlah Responden } & \multicolumn{2}{c}{ Persentase } \\
\cline { 2 - 5 } & Ya & Tidak & Ya & Tidak \\
\hline 1 & 22 & 3 & $88 \%$ & $12 \%$ \\
2 & 25 & - & $100 \%$ & $0 \%$ \\
3 & 23 & 2 & $92 \%$ & $8 \%$ \\
4 & 24 & 1 & $96 \%$ & $4 \%$
\end{tabular}


Pembelajaran Mahārat al-Kalām pada Program Kursus Bahasa Arab Spesial Ramadan di Pondok Pesantren Darul Lughah Waddirasatil Islamiyah, Pamekasan, Madura

\begin{tabular}{ccccc}
5 & 25 & - & $100 \%$ & $0 \%$ \\
6 & 23 & 2 & $92 \%$ & $8 \%$ \\
7 & 25 & - & $100 \%$ & $0 \%$ \\
8 & 22 & 3 & $88 \%$ & $12 \%$ \\
9 & 25 & - & $100 \%$ & $0 \%$ \\
10 & 25 & - & $100 \%$ & $0 \%$ \\
\hline
\end{tabular}

Tabel 3. Efektivitas pembelajaran mahārat al-kalām pada tingkat mutaqaddim

\begin{tabular}{ccccc}
\hline \multirow{2}{*}{ Nomor Soal } & \multicolumn{2}{c}{ Jumlah Responden } & \multicolumn{2}{c}{ Persentase } \\
\cline { 2 - 5 } & Ya & Tidak & Ya & Tidak \\
\hline 1 & 15 & - & $100 \%$ & $0 \%$ \\
2 & 15 & - & $100 \%$ & $0 \%$ \\
3 & 15 & - & $100 \%$ & $0 \%$ \\
4 & 15 & - & $100 \%$ & $0 \%$ \\
5 & 14 & - & $100 \%$ & $0 \%$ \\
6 & 14 & - & $100 \%$ & $0 \%$ \\
7 & 15 & - & $100 \%$ & $0 \%$ \\
8 & 13 & 2 & $86,7 \%$ & $13,7 \%$ \\
9 & 14 & 1 & $93,3 \%$ & $6,7 \%$ \\
10 & 15 & - & $100 \%$ & $0 \%$ \\
\hline
\end{tabular}

Berdasarkan Tabel 1, 2, dan 3, dapat diketahui bahwa soal nomor 1 menandakan pembelajaran mahārat al-kalām pada program kursus ini dinyatakan efektif dalam memberikan bekal yang cukup dalam bahasa Arab. Soal nomor 2 dinyatakan efektif dalam meningkatkan kemampuan berbicara bahasa Arab dari kemampuan yang sebelumnya. Soal nomor 3 dinyatakan efektif dalam menunjang kemampuan peserta dalam berbicara bahasa Arab. Soal nomor 4 dinyatakan efektif dalam mengembalikan memori kemampuan berbahasa peserta kursus yang sudah banyak terlupakan. Sementara itu, soal nomor 5 dinyatakan efektif dalam memberikan banyak kesempatan pada peserta untuk berbicara bahasa Arab.

Soal nomor 6 menandakan bahwa pembelajaran mahārat al-kalām pada program kursus ini dinyatakan efektif dalam mempermudah peserta untuk berbicara bahasa Arab. Soal nomor 7 menandakan efektif dalam memberikan banyak pola-pola kalimat yang peserta dapatkan untuk diterapkan dalam berbicara bahasa Arab. Soal nomor 8, efektif dalam meningkatkan kualitas kemampuan berbicara bahasa Arab peserta dari segi qawā id al-lughah. Soal nomor 9, efektif dalam meningkatkan kualitas kemampuan berbicara bahasa Arab peserta dari segi mufradāt. Sementara itu, soal nomor 10 menandakan efektif dalam berbicara bahasa Arab dengan lancar.

Berdasarkan pemaparan data di atas dapat disimpulkan bahwa efektivitas pembelajaran mahārat al-kalām pada program kursus bahasa Arab di PP DLWI Pamekasan, Madura, dinyatakan sangat baik. Hal tersebut menandakan bahwa pembelajaran mahārat al-kalām sangat efektif, dan ini dibuktikan dengan persentase rata-rata yang diberikan oleh peserta kursus sebesar 87,33\%. 


\section{Efisiensi Pembelajaran Mahārat al-Kalām}

Tabel 4. Efisiensi pembelajaran mahārat al-kalām pada tingkat mubtadi'

\begin{tabular}{|c|c|c|c|c|}
\hline \multirow{2}{*}{ Nomor Soal } & \multicolumn{2}{|c|}{ Jumlah Responden } & \multicolumn{2}{|c|}{ Persentase (\%) } \\
\hline & $\mathrm{Ya}$ & Tidak & Ya & Tidak \\
\hline 1 & 25 & 5 & $83 \%$ & $17 \%$ \\
\hline 2 & 30 & - & $100 \%$ & $0 \%$ \\
\hline 3 & 26 & 4 & $87 \%$ & $13 \%$ \\
\hline 4 & 25 & 5 & $83 \%$ & $17 \%$ \\
\hline 5 & 25 & 5 & $83 \%$ & $17 \%$ \\
\hline 6 & 25 & 5 & $83 \%$ & $17 \%$ \\
\hline 7 & 26 & 4 & $87 \%$ & $13 \%$ \\
\hline 8 & 26 & 4 & $87 \%$ & $13 \%$ \\
\hline 9 & 26 & 4 & $87 \%$ & $13 \%$ \\
\hline 10 & 26 & 4 & $87 \%$ & $13 \%$ \\
\hline 11 & 26 & 4 & $87 \%$ & $13 \%$ \\
\hline 12 & 26 & 4 & $87 \%$ & $13 \%$ \\
\hline 13 & 27 & 3 & $90 \%$ & $10 \%$ \\
\hline 14 & 26 & 4 & $87 \%$ & $13 \%$ \\
\hline 15 & 26 & 4 & $87 \%$ & $13 \%$ \\
\hline 16 & 26 & 4 & $87 \%$ & $13 \%$ \\
\hline 17 & 30 & - & $100 \%$ & $0 \%$ \\
\hline 18 & 27 & 3 & $90 \%$ & $10 \%$ \\
\hline 19 & 27 & 3 & $90 \%$ & $10 \%$ \\
\hline 20 & 28 & 2 & $93 \%$ & $7 \%$ \\
\hline & Rata-rata & & $88,25 \%$ & $11,75 \%$ \\
\hline
\end{tabular}

Tabel 5. Efisiensi pembelajaran mahārat al-kalām pada tingkat mutawassit

\begin{tabular}{ccccc}
\hline \multirow{2}{*}{ Nomor Soal } & \multicolumn{2}{c}{ Jumlah Responden } & \multicolumn{2}{c}{ Persentase } \\
\cline { 2 - 5 } & Ya & Tidak & Ya & Tidak \\
\hline 1 & 25 & - & $100 \%$ & $0 \%$ \\
2 & 25 & - & $100 \%$ & $0 \%$ \\
3 & 25 & - & $100 \%$ & $0 \%$ \\
4 & 19 & 6 & $76 \%$ & $24 \%$ \\
5 & 16 & 9 & $64 \%$ & $36 \%$ \\
6 & 20 & 5 & $80 \%$ & $20 \%$ \\
7 & 25 & - & $100 \%$ & $0 \%$ \\
8 & 25 & - & $100 \%$ & $0 \%$ \\
9 & 25 & - & $100 \%$ & $0 \%$ \\
10 & 25 & - & $100 \%$ & $0 \%$ \\
11 & 25 & - & $100 \%$ & $0 \%$ \\
12 & 21 & 4 & $84 \%$ & $16 \%$ \\
13 & 21 & 4 & $84 \%$ & $16 \%$ \\
14 & 21 & 4 & $84 \%$ & $16 \%$ \\
15 & 21 & 4 & $84 \%$ & $16 \%$
\end{tabular}


Pembelajaran Mahārat al-Kalām pada Program Kursus Bahasa Arab Spesial Ramadan di Pondok Pesantren Darul Lughah Waddirasatil Islamiyah, Pamekasan, Madura

\begin{tabular}{ccccc}
16 & 19 & 6 & $76 \%$ & $24 \%$ \\
17 & 25 & - & $100 \%$ & $0 \%$ \\
18 & 25 & - & $100 \%$ & $0 \%$ \\
19 & 25 & - & $100 \%$ & $0 \%$ \\
20 & 21 & 4 & $84 \%$ & $16 \%$ \\
\hline
\end{tabular}

Tabel 6. Efisiensi pembelajaran mahārat al-kalām pada tingkat mutaqaddim

\begin{tabular}{|c|c|c|c|c|}
\hline \multirow{2}{*}{ Nomor Soal } & \multicolumn{2}{|c|}{ Jumlah Responden } & \multicolumn{2}{|c|}{ Persentase (\%) } \\
\hline & $\mathrm{Ya}$ & Tidak & $\mathrm{Ya}$ & Tidak \\
\hline 1 & 15 & - & $100 \%$ & $0 \%$ \\
\hline 2 & 15 & - & $100 \%$ & $0 \%$ \\
\hline 3 & 15 & - & $100 \%$ & $0 \%$ \\
\hline 4 & 13 & 2 & $87 \%$ & $13 \%$ \\
\hline 5 & 13 & 2 & $87 \%$ & $13 \%$ \\
\hline 6 & 13 & 2 & $87 \%$ & $13 \%$ \\
\hline 7 & 15 & - & $100 \%$ & $0 \%$ \\
\hline 8 & 15 & - & $100 \%$ & $0 \%$ \\
\hline 9 & 15 & - & $100 \%$ & $0 \%$ \\
\hline 10 & 15 & - & $100 \%$ & $0 \%$ \\
\hline 11 & 12 & 3 & $80 \%$ & $20 \%$ \\
\hline 12 & 12 & 3 & $80 \%$ & $20 \%$ \\
\hline 13 & 15 & - & $100 \%$ & $0 \%$ \\
\hline 14 & 15 & - & $100 \%$ & $0 \%$ \\
\hline 15 & 15 & - & $100 \%$ & $0 \%$ \\
\hline 16 & 12 & 3 & $80 \%$ & $20 \%$ \\
\hline 17 & 15 & - & $100 \%$ & $0 \%$ \\
\hline 18 & 15 & - & $100 \%$ & $0 \%$ \\
\hline 19 & 15 & - & $100 \%$ & $0 \%$ \\
\hline 20 & 12 & 3 & $80 \%$ & $20 \%$ \\
\hline & Rata-rata & & $94,05 \%$ & $5,95 \%$ \\
\hline
\end{tabular}

Berdasarkan tabel 4, 5, dan 6 dapat diketahui bahwa soal nomor 1 menandakan bahwa pembelajaran mahārat al-kalām pada program kursus ini dinyatakan efisien dalam pembagian waktu kursus dengan istirahat. Soal nomor 2 efisien dalam pembagian waktu kursus dengan ibadah. Soal nomor 3 efisien dalam pembagian waktu kursus dengan waktu kerjanya. Soal nomor 4 efisien berdasarkan durasi pembelajarannya. Soal nomor 5 efisien berdasarkan durasi kursusnya. Soal nomor 6 efisien berdasarkan pemanfaatan waktunya. Soal nomor 7 efisien berdasarkan kepuasan terhadap kompetensi gurunya. Soal nomor 8 efisien berdasarkan kepuasan terhadap metode yang diajarkan oleh gurunya. Soal nomor 9 efisien berdasarkan kepuasan terhadap materi yang diajarkan oleh gurunya. Sementara itu, soal nomor 10 menandakan efisien berdasarkan kepuasan terhadap materi yang diajarkan sesuai dengan kemampuan peserta.

Soal nomor 11 menandakan bahwa pembelajaran mahārat al-kalām pada program kursus ini dinyatakan efisien berdasarkan kepuasan terhadap medianya. Soal nomor 12 efisien berdasarkan 
kepuasan terhadap fasilitasnya. Soal nomor 13 efisien berdasarkan biaya mengikuti kursus ini. Soal nomor 14 efisien berdasarkan kesepadanan biaya dengan ilmu yang diperoleh. Soal nomor 15 efisien berdasarkan pengeluaran dalam biayanya. Soal nomor 16 efisien berdasarkan biaya kursus dijangkau oleh semua kalangan. Soal nomor 17 efisien berdasarkan biaya kursusnya. Soal nomor 18 efisien berdasarkan ketidakbosanan dalam mengikuti kursus ini. Soal nomor 19 efisien berdasarkan semangat belajar peserta. Sementara itu, soal nomor 20 menandakan bahwa efisien berdasarkan tenaga yang digunakan.

Berdasarkan pemaparan data di atas dapat disimpulkan bahwa efisiensi pembelajaran mahārat al-kalām pada program kursus bahasa Arab di PP DLWI Pamekasan, Madura, dinyatakan sangat baik. Hal tersebut menandakan bahwa pembelajaran mahārat al-kalām sangat efisien, dan ini dibuktikan dengan persentase rata-rata yang diberikan oleh peserta kursus sebesar 90,8\%.

\section{Pembahasan}

A. Proses Pembelajaran Mahārat al-Kalām pada Program Kursus Bahasa Arab Spesial Ramadan

Hady (2019), mengutip pendapat Rushdī Ahmad Ṭu'aymah, menjelaskan bahwa dalam konteks pembelajaran bahasa Arab, mahārat al-kalām merupakan keterampilan pokok yang harus dikuasai peserta didik dan menjadi salah satu tujuan akhir pembelajaran bahasa Asing. Proses pembelajaran tentunya tidak terlepas dari sumber belajar, yakni bahan ajar. Bahan ajar adalah segala bahan (baik informasi, alat maupun teks) yang disusun secara sistematis, yang menampilkan sosok utuh dari kompetensi yang akan dikuasai peserta didik dan digunakan dalam proses pembelajaran. Buku yang digunakan oleh peserta kursus dalam pembelajaran mahārat al-kalām pada program kursus spesial Ramadan disusun oleh pendiri PP DLWI, K.H. Ahmad Ghazali Salim, Lc., M.Ag.

Tingkat mubtadi' menggunakan buku Majmü'at al-lughah al-'Arabiyah yang mengajarkan tata cara menyusun kalimat dengan benar dan mudah, serta tidak sulit untuk diterapkan dan dipelajari pada tingkatan ini, seperti susunan kalimat sehari-hari yang dilakukan oleh semua orang. Sementara itu, buku al-Muhādathah wa-al-Muțāla'ah jilid 1 digunakan untuk membantu kelancaran peserta kursus dalam berbicara bahasa Arab sehari-hari. Pada tingkat mutawassit dan mutaqaddim juga menggunakan buku al-Muhädathah wa-al-Mutāla'ah jilid 2 sebagai panduan dalam berbicara bahasa Arab, Majmü'at al-lughah al-'Arabiyah, dan al-Lughah al-Sahafìah waal-'Așīyah, sedangkan buku Turuq al-Tadris hanya digunakan pada tingkat mutaqaddim saja yang berisi tentang tata cara mengajar atau metode mengajar dengan baik. Namun, penggunaan semua buku yang disusun dalam lembaga kursus tersebut tidak akan efektif dan efisien apabila tidak disampaikan dengan metode pembelajaran yang baik.

Proses pembelajaran mahārat al-kalām pada kursus spesial Ramadan di PP DLWI tidak lepas dari penggunaan metode pembelajaran. Nuha (2012) menjelaskan bahwa metode pembelajaran adalah seperangkat cara yang digunakan oleh seorang guru dalam menyampaikan ilmu atau transfer ilmu kepada anak didiknya dalam proses pembelajaran. Metode yang sering digunakan dalam pembelajaran mahārat al-kalām di PP DLWI, yaitu metode langsung (direct method), metode diskusi (munāqashah), metode percakapan (mubādathah), dan metode debat (mujādalah).

Proses pembelajaran mahārat al-kalām pada tingkat mubtadi' menggunakan metode langsung untuk memperkenalkan suatu benda yang tidak dipahami oleh peserta. Penerapannya yaitu dengan cara observasi ke luar kelas dan mengenalkan berbagai benda secara langsung menggunakan bahasa 
Arab. Tingkat mubtadi' juga ditekankan pada pengenalan mufradāt dan dibantu untuk mempraktikkannya dalam berbicara bahasa Arab. Tujuannya agar peserta didik mampu mengucapkan kosakata dengan benar, memahami maknanya, mengetahui proses perubahannya (ishtiqāq), dan mengetahui bagaimana merangkaikannya menjadi sebuah kalimat. Lebih dari itu, diharapakan peserta didik juga mampu menggunakan mufradāt tersebut dalam konteks kalimat yang benar (Syamsudin \& Damaianti, 2011, p. 120).

Proses pembelajaran mahārat al-kalām pada tingkat mutawaasit menggunakan metode munāqashah wa-al-mubādathah. Metode tersebut dipilih oleh para mentor (mushrif) PP DLWI karena pada tingkat mutawassit lebih difokuskan pada pengembangan bahasa Arab. Wa Muna (2011) menjelaskan bahwa metode yang tepat untuk diterapkan dalam pembelajaran adalah metode yang dapat menstimulasi peserta didik untuk berbicara dengan menggunakan bahasa Arab. Salah satunya adalah metode mubādathah, yaitu metode penyajian bahan pelajaran bahasa Arab melalui percakapan. Percakapan itu dapat terjadi antara pendidik dengan peserta didik, atau antara peserta didik dengan peserta didik, sehingga dapat memperkaya perbendaharaan kata. (Anshor, 2009, p. 55).

Proses pembelajaran mahārat al-kalām pada tingkat mutaqaddim juga menggunakan metode yang sama dengan tingkat mutawassit, yakni metode munāqashah, muhādathah, dan mujädalah. Metode tersebut bertujuan untuk menyajikan bahan pembelajaran bahasa Arab melalui percakapan yang disertai dengan penambahan mufradāt atau kosakata baru saat proses percakapan berlangsung. Tujuan penggunaan metode muḅädathah secara khusus pada tingkat mutaqaddim adalah agar peserta didik dapat berkomunikasi menggunakan bahasa Arab secara lisan dengan baik, lancar, dan juga benar. Selain itu, para santri juga diajarkan țuruq al-tadrīs (tata cara mengajar), dan metode lain seperti metode al-ta'bìr al-shafahì, muqābalah, khitäbah, dan mujädalah. Jadi, tidak hanya menggunakan satu metode saja, setiap pendidik juga memiliki kewenangan dan kebebasan untuk memilih metode yang sesuai dengan kebutuhan pelajar (Effendy, 2012, p. 96).

Proses pembelajaran mahārat al-kalām di PP DLWI menggunakan media untuk mendukung proses pembelajaran. Media tersebut digunakan untuk mempermudah guru dalam menyampaikan pesan dari materi pelajaran. Oleh karena itu, media mempunyai peran penting dalam menyampaikan pembelajaran bahasa asing seperti bahasa Arab (Rosyidi, 2009, pp. 19-20). Media yang digunakan pada proses pembelajaran mahārat al-kalām yaitu, papan tulis, gambar, lukisan, foto, LCD, proyektor, dan VCD. Penelitian yang dilakukan oleh Mardliyah (2009) menjelaskan bahwa pelaksanaan pembelajaran dengan menggunakan media VCD dan audio dengan memperhatikan motivasi berprestasi siswa sangat mempengaruhi pencapaian prestasi belajar bahasa Arab.

Keberhasilan proses pembelajaran dapat diukur dari hasil evaluasi. Evaluasi pembelajaran adalah proses untuk menentukan nilai belajar dan pembelajaran yang telah dilaksanakan dengan melalui kegiatan penilaian (Miladya, 2015, pp. 180-181). Bentuk evaluasi dalam pembelajaran mahārat alkalām di PP. DLWI adalah tes lisan yang dinilai dari percakapan secara langsung, kegiatan diskusi, dan kegiatan monolog atau berpidato dengan menampilkan hasil belajarnya di depan kelas. Miladya (2015) juga menjelaskan bahwa dalam pembelajaran bahasa Arab khususnya pembelajaran mahārat al-kalām, evaluasinya menggunakan tes lisan. Tes lisan ini bertujuan untuk mengukur sejauh mana peserta didik dapat berbicara bahasa Arab sehingga para peserta didik diharapkan mampu berkomunikasi dengan menggunakan bahasa Arab yang baik dan benar. 
B. Efektivitas Pembelajaran Mahārat al-Kalām pada Program Kursus Bahasa Arab Spesial Ramadan

Efektivitas pembelajaran mahārat al-kalām pada program kursus bahasa Arab spesial Ramadan di PP DLWI, Pamekasan, Madura, termasuk ke dalam kategori sangat efektif. Hal tersebut dibuktikan dengan skor rerata respon peserta didik terhadap angket efektivitas pembelajaran mahārat al-kalām. Rerata skor yang diperoleh pada tingkat mubtadi' sebesar 87,33\%, pada tingkat mutawassit sebesar 95,6\%, dan pada tingkat mutaqaddim sebesar 98\%.

Hasil respon peserta tingkat mubtadi' menunjukkan bahwa pada angket efektivitas pembelajaran mahārat al-kalām memiliki rerata skor jawaban "ya" sebesar 87,33\%, yang menandakan bahwa pembelajaran mahārat al-kalām pada kegiatan kursus tersebut efektif. Para santri menganggap bahwa kegiatan kursus tersebut dapat memberi bekal yang cukup bagi peserta kursus sebagai pelajar bahasa Arab, dan dapat meningkatkan kemampuan mereka dalam berbicara bahasa Arab. Hal tersebut sejalan dengan yang disampaikan oleh Firminus (2013) yang menyatakan pembelajaran yang efektif dilihat dari tingkat pencapaian tujuan suatu pelatihan (kursus). Pencapaian tujuan tersebut dapat berupa peningkatan pengetahuan dan keterampilan peserta didik serta melalui proses pembelajaran berlangsung.

Hasil respon peserta tingkat mutawassit menunjukkan bahwa efektivitas pembelajaran mahārat al-kalām memiliki rerata skor jawaban “ya” sebesar 95,6\%, yang menandakan bahwa pembelajaran mahārat al-kalām pada kegiatan kursus tersebut efektif. Pernyataan yang memperoleh skor maksimal di antaranya adalah yang menyatakan bahwa program kursus ini dapat meningkatkan kemampuan berbicara bahasa Arab peserta dari kemampuan yang sebelumnya, dan dapat memberikan banyak kesempatan pada peserta untuk berbicara bahasa Arab. Hal tersebut sesuai dengan yang dijelaskan oleh Rosyidi dan Ni'mah (2012), bahwa salah satu prinsip dari pembelajaran mahārat al-kalām adalah memperbanyak latihan, seperti latihan membedakan pengucapan bunyi, latihan mengungkapkan ide-ide, dan lain sebagainya.

Hasil respon peserta tingkat mutaqaddim menunjukkan bahwa efektivitas pembelajaran mahārat al-kalām memiliki rerata skor jawaban "ya" sebesar 98\%, yang menandakan bahwa pembelajaran mahārat al-kalām pada kegiatan kursus tersebut efektif. Hanya ada dua pernyataan yang tidak terjawab $100 \%$ oleh peserta mutaqaddim yakni mengenai peningkatan kemampuan berbicara bahasa Arab peserta dari segi mufradāt, dan dari segi qawāid al-lughah. Skor dari kedua aspek pernyataan tersebut tergolong sangat baik, yakni sebesar 93,3\%. Keberadaan qawāid dipandang sangat penting seperti pentingnya penggunaan mufradāt dalam suatu rangkaian kalimat. Mempelajari qawā $i d$, meskipun bukan menjadi tujuan utama, akan tetapi ia merupakan media untuk mengevaluasi kemampuan kalām dan kitābah peserta kursus. Jadi, tanpa menggunakan qawāid, akan sulit tercipta sebuah komunikasi yang baik dan efektif (Zainuddin, 2005, p. 96).

C. Efisiensi Pembelajaran Mahārat al-Kalām pada Program Kursus Bahasa Arab Spesial Ramadan Eisiensi pembelajaran mahārat al-kalām pada program kursus bahasa Arab spesial Ramadan di PP DLWI, Pamekasan, Madura, termasuk ke dalam kategori sangat efisien. Hal tersebut dibuktikan dengan skor rerata respon peserta didik terhadap angket efisiensi pembelajaran mahārat al-kalām. Rerata skor yang diperoleh pada tingkat mubtadi' sebesar $88,25 \%$, pada tingkat mutawassit sebesar 90,8\%, dan pada tingkat mutaqaddim sebesar 94,05\%. 
Hasil respon peserta tingkat mubtadi' menunjukkan bahwa efisiensi pembelajaran mahārat alkalām memiliki rerata skor jawaban "ya” sebesar 88,25\%, yang menandakan bahwa pembelajaran mahārat al-kalām pada kegiatan kursus tersebut efisien. Para santri merasa metode yang digunakan guru dalam pembelajaran sangat baik dan merasa mudah dalam memahami materi yang disampaikan, serta tidak terlalu menguras waktu, tenaga, dan biaya dari ilmu yang didapatkan. Hal tersebut sesuai dengan yang disampaikan oleh Wulandari (2016), seorang guru harus memiliki berbagai pendekatan, model, dan strategi dalam pembelajaran yang menyenangkan, sehingga peserta didik mampu menunjukkan minat, bakat, kemampuan yang dimilikinya.

Hasil respon peserta tingkat mutawassit menunjukkan bahwa efisiensi pembelajaran mabārat al-kalām memiliki rerata skor jawaban "ya” sebesar 90,8\%, yang menandakan bahwa pembelajaran mahārat al-kalām pada kegiatan kursus tersebut sangat efisien. Beberapa pernyataan yang memperoleh skor maksimal di antaranya adalah yang menyatakan bahwa media pembelajaran yang digunakan pada program kursus tersebut sangat mendukung sebagai perantara dalam menyampaikan materi pembelajaran kursus. Hal tersebut tentunya sesuai dengan yang dijelaskan oleh Musakkir (2015), guru dalam membuat media pembelajaran harus memperhatikan peserta didik dalam hal apa pun, agar dalam penggunaan media tersebut nantinya akan sangat bermakna untuk peserta didik. Sementara itu, Hasil respon peserta tingkat mutaqaddim menunjukkan hasil bahwa efisiensi pembelajaran mahārat al-kalām memiliki rerata skor jawaban "ya" sebesar 94,5\% dari 15 peserta. Hal tersebut menandakan bahwa pembelajaran mahārat al-kalām pada kegiatan kursus tersebut sangat efisien. Beberapa pertanyaan memperoleh jawaban yang maksimal di antaranya adalah program kursus spesial Ramadan ini sangat menyenangkan dari segala aspeknya, sehingga membuat para santri menjadi lebih semangat dalam belajar. Darmansyah (2010) menjelaskan bahwa strategi pembelajaran yang menyenangkan adalah strategi yang digunakan oleh guru untuk menciptakan lingkungan belajar yang efektif dan efisien dalam menerapkan kurikulum, menyampaikan materi, dan memudahkan proses belajar peserta didik.

\section{Simpulan}

Proses pembelajaran mahārat al-kalām pada program kursus bahasa Arab spesial Ramadan di PP DLWI, Pamekasan, Madura, dibagi ke dalam tiga tingkatan, yaitu mubtadi, mutawassit, dan mutaqaddim. Pembelajaran tersebut terdiri dari pemberian materi pembelajaran, metode, media pembelajaran, dan evaluasi. Hasil efektivitas pembelajaran mahārat al-kalām pada tingkat mubtadi' sebesar 87,33\% (sangat efektif), tingkat mutawassit sebesar 95,6\% (sangat efektif), dan tingkat mutaqaddim sebesar $98 \%$ (sangat efektif). Sementara itu, hasil efisiensi pembelajaran mahārat alkalām pada tingkat mubtadi' sebesar 88,25\% (sangat efisien), tingkat mutawassit sebesar 90,88\% (sangat efisien), dan tingkat mutaqaddim sebesar 94,05\% (sangat efisien). Dengan demikian, penelitian ini membuktikan bahwa pembelajaran mahārat al-kalām pada program kursus ini terbukti efektif dan efisien.

\section{Daftar Rujukan}

Anshor, A. M. (2009). Pengajaran bahasa Arab: Media dan metode-metodenya. Yogyakarta: Teras. Arsyad, A. (2010). Bahasa Arab dan metode pengajarannya. Yogyakarta: Pustaka Pelajar 
Arikunto, S. (2005). Manajemen penelitian. Jakarta: Rineka Cipta.

Darmansyah. (2010). Strategi pembelajaran menyenangkan dengan humor. Jakarta: Bumi Aksara.

Effendy, A. F. (2012). Metodologi pengajaran bahasa Arab. Malang: Misykat.

Farkhana, N. F. (2017). Pembelajaran mabarab al kalam siswa kelas unggulan di Mts N 2 Banjarnegara tabun pelajaran 2016/2017 (Skripsi, Jurusan Pendidikan Bahasa Arab Fakultas Tarbiyah dan Ilmu Pendidikan, Institut Agama Islam Negeri Purwokerto). Retrieved from http://repository.iainpurwokerto.ac.id/3539/

Firminus. (2013). Penerapan model kooperatif tipe student team achievement division untuk meningkatkan efektivitas belajar matematika. Jurnal Pendidikan dan Pembelajaran Khatulistiwa, 2(7). Retrieved from http://jurnal.untan.ac.id/index.php/jpdpb/article/view/2453

Hady, Y. (2019). Pembelajaran mahārat al-kalām menurut Rusdy Ahmad Thu'aimah dan Mahmud Kamil al-Naqah. al Mahāra: Jurnal Pendidikan Babasa Arab, 5(1), 63-84. doi:10.14421/almahara.2019.051-04

Harahap, P. (2017). Perbandingan pengajaran keterampilan berbicara bahasa Arab dan bahasa Inggris di Sekolah Tinggi Agama Islam Negeri Curup. Arabiyatuna:Jurnal Babasa Arab, 1(2), 153-178. doi:10.29240/jba.v1i2.323

Hermawan, A. (2011). Metodologi pembelajaran bahasa Arab. Bandung: PT Remaja Rosdakarya.

Mardliyah, S. (2009). Pengarub penggunaan media audio visual (VCD) dan media audio terbadap pencapaian prestasi belajar bahasa Arab ditinjau dari motivasi berprestasi siswa: Studi eksperimen pada kelas VIII di Mts NKaranganyar dan kelas VIII di Mts NGondangrejo tabun pelajaran 2008/2009 (Tesis, Program Studi Teknologi Pendidikan, Program Pascasarjana Universitas Sebelas Maret Surakarta). Retrieved from https://digilib.uns.ac.id/dokumen/detail/14547/

Miladya, J. (2015). Evaluasi dalam pembelajaran bahasa Arab. In Kreativitas dan Inovasi dalam Pembelajaran Babasa Arab di Indonesia. Prosiding Konferensi Nasional Bahasa Arab (Konasbara), Universitas Negeri Malang, Indonesia. Retrieved from http://prosiding.arabum.com/index.php/konasbara/article/view/21

Muna, W. (2011). Metodologi pembelajaran bahasa Arab. Yogyakarta: Teras.

Musakkir. (2015). Pengaruh media pembelajaran dan motivasi belajar terhadap hasil belajar matematika siswa kelas IV Sekolah Dasar Kabupaten Tanah Tidung. Jurnal Pendidikan Dasar, 6(1), 36-47. Retrieved from http://pps.unj.ac.id/journal/jpd/article/view/313

Nuha, U. (2012). Metodologi super efektif pembelajaran bahasa Arab. Yogyakarta: DIVA Press.

Rosyidi, A. W. (2009). Media pembelajaran bahasa Arab. Malang: UIN Maliki Press.

Rosyidi, A. W., \& Ni'mah, M. (2012). Memahami konsep dasar pembelajaran bahasa Arab. Malang: UIN Maliki Press

Syamsudin, \& Damaianti. (2011). Metode penelitian pendidikan babasa. Bandung: Remaja Rosdakarya.

Wulandari, D. (2016). Model pembelajaran yang menyenangkan berbasis peminatan. Jurnal Inspirasi Pendidikan Universitas Kanjuruban Malang, 6(2), 851-856. doi:10.21067/jip.v6i2.1318

Zainuddin, R. (2005). Metodologi dan strategi alternatif pembelajaran bahasa Arab. Yogyakarta: Puspita Rihlah Group. 